\title{
Sleeping giants: cardiac metastases from gastrointestinal neuroendocrine neoplasms
}

\author{
Chrissy Bolton, ${ }^{1}$ Kyriacos Mouyis, ${ }^{1}$ Themistoklis Liassides, ${ }^{2}$ Constantinos G Missouris ${ }^{1,2}$
}

${ }^{1}$ Department of Cardiology, Frimley Health NHS Foundation Trust, Frimley, UK

${ }^{2}$ Department of Medicine, University of Cyprus Medical School, Nicosia, Cyprus

\section{Correspondence to} Constantinos G Missouris, dinos.missouris@nhs.net

Accepted 1 November 2018

\section{DESCRIPTION}

Neuroendocrine neoplasms affecting the heart are a rare but important condition to diagnose as they carry an adverse prognosis. We report an asymptomatic patient who presented with an incidental finding of a huge mass in the right side of the heart.

A previously fit man was investigated elsewhere for abnormal liver function tests with a liver biopsy, undertaken via the transjugular approach. During the procedure, severe tricuspid regurgitation was discovered. A transthoracic echocardiogram identified a $6 \times 6 \times 4 \mathrm{~cm}$ heterogeneous vascular mass infiltrating the right ventricular free wall and distorting the annulus of the tricuspid valve, obliterating the right ventricle (figure 1). The tricuspid valve leaflets were tethered and non-coapting causing free-flowing tricuspid regurgitation.

The treating physicians' differential included a primary cardiac neoplasm (angiosarcoma), metastasis and cardiac lymphoma. A thoracic magnetic resonance scan, median sternotomy and open biopsy of the mass was undertaken to elucidate aetiology. Functional imaging could have helped distinguish between a primary and secondary neoplasm. Within days of the open biopsy, the patient deteriorated rapidly, experiencing profuse diarrhoea and exertional dyspnoea. Histopathology results were not available, and clinical suspicion of carcinoid syndrome was low; however, 5-hydroxyindoleacetic acid tests could have aided diagnosis. Colonoscopy did not identify any lesions.
Histopathology evaluation identified a well-differentiated (G1) neuroendocrine neoplasm, with a proliferation index under $1 \%$ and mitotic count of $0 / 10$ high power fields. Immunostaining was positive for synaptophysin, chromogranin, serotonin and CDX-2 making spread from a gastro-intestinal primary likely. A contrast-enhanced CT scan looking for a primary neuroendocrine lesion identified an avidly enhancing $1.2 \mathrm{~cm}$ intraluminal lesion within the terminal ileum, with an adjacent calcified ileocolic nodal mass. The cardiac mass was now measured at $8 \times 6 \times 4.9 \mathrm{~cm}$ (figure 1 ). Three weeks following the biopsy, he presented to the emergency department with hypotension and a reduced level of consciousness. Despite supportive measures, he sadly died of cardiogenic shock.

Neuroendocrine neoplasms are epithelial neoplasms mostly arising from the gastro-enteropancreatic system, with an incidence of around 2.5-5 per 100000 persons. ${ }^{1}$ In serotonin-secreting neoplasms, carcinoid syndrome may develop as hepatic function becomes compromised. This is characterised by flushing, diarrhoea and bronchoconstriction. Cardiac metastases of neuroendocrine neoplasms have been reported up to $5 \mathrm{~cm}$ in diameter previously. ${ }^{1}$ Structural deformity contributed to tricuspid regurgitation in this case; however, cardiac valve changes may also occur as a result of elevated circulating neurohormones and vasoactive substances. ${ }^{2}$ Carcinoid heart disease arising from fibrosis and smooth muscle
Check for updates

(C) BMJ Publishing Group Limited 2018. No commercial re-use. See rights and permissions. Published by BMJ.

To cite: Bolton C, Mouyis K, Liassides T, et al. BMJ Case Rep 2018;11:e227197. doi:10.1136/bcr-2018227197
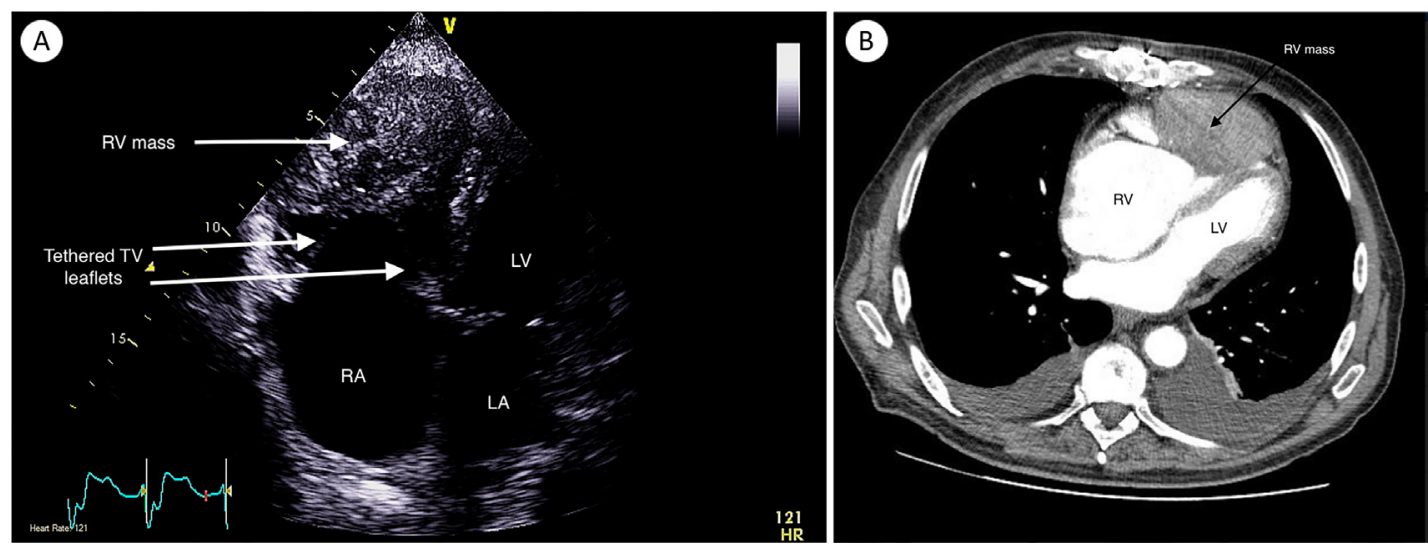

Figure 1 (A) Apical four-chamber transthoracic echocardiography image showing right ventricular mass and (B) CT scan of chest in axial section showing right ventricular mass. LA, left atrium; LV, left ventricle; RA, right atrium; RV, right ventricle; TV, tricuspid valve. 
proliferation classically causes tricuspid valve regurgitation too. ${ }^{2}$

This case demonstrates that neuroendocrine neoplasms originating from the midgut may present asymptomatically, through detection of cardiac metastases. It highlights the significance of cardiac imaging modalities, median sternotomy and open biopsy in reaching a diagnosis.

\section{Learning points}

- Giant cardiac metastases can be the presenting symptom in neuroendocrine neoplasms that are otherwise asymptomatic.

- Open biopsy may be fundamental in acquiring a diagnosis but may pose a decompensation risk.

- Functional imaging may provide a valuable tool in characterising neuroendocrine tumours.
Acknowledgements We would like to thank the patient's next of kin for assisting us in sharing this case.

Contributors Acquisition of data and manuscript writing: CB. Acquisition of data and manuscript review: KM. Interpretation of data and manuscript review: TL. Conception of case and manuscript review: CGM.

Funding The authors have not declared a specific grant for this research from any funding agency in the public, commercial or not-for-profit sectors.

Competing interests None declared.

Patient consent Next of kin consent obtained.

Provenance and peer review Not commissioned; externally peer reviewed.

\section{REFERENCES}

1 Jann $\mathrm{H}$, Wertenbruch T, Pape U, et al. A matter of the heart: myocardial metastases in neuroendocrine tumors. Horm Metab Res 2010:42:967-76.

2 Noordzij W, van Beek AP, Tio RA, et al. Myocardial metastases on 6-[18F] fluoro-LDOPA PET/CT: a retrospective analysis of 116 serotonin producing neuroendocrine tumour patients. PLoS One 2014;9:e112278.

Copyright 2018 BMJ Publishing Group. All rights reserved. For permission to reuse any of this content visit https://www.bmj.com/company/products-services/rights-and-licensing/permissions/

BMJ Case Report Fellows may re-use this article for personal use and teaching without any further permission.

Become a Fellow of BMJ Case Reports today and you can:

- Submit as many cases as you like

- Enjoy fast sympathetic peer review and rapid publication of accepted articles

- Access all the published articles

Re-use any of the published material for personal use and teaching without further permission

For information on Institutional Fellowships contact consortiasales@bmjgroup.com

Visit casereports.bmj.com for more articles like this and to become a Fellow 